\title{
TODO ARTE ES RECREACIÓN DE LA REALIDAD ${ }^{* 1}$
}

\author{
François Fédier ${ }^{2}$
}

El arte está presente en todas partes donde hay hombres. Es un fenómeno tan íntimamente ligado a la humanidad que parece imposible pasarlo por alto por poco que planteemos la pregunta por saber quiénes somos.

¿Cómo pensar este fenómeno?

Uno de los caminos más simples consiste en escuchar a un artista. En nuestro siglo, Proust está entre aquellos que han reflexionado más intensamente sobre su arte y el arte en general. En las notas crítica que datan de 1909, en que toma cuerpo - a medida que se precisa su visión del arte- el futuro En busca del tiempo perdido, escribe:

esta recreación de la realidad que es todo el arte ${ }^{3}$.

El arte es esencialmente "recreación de la realidad". Esto nos parece obvio, hasta el punto mismo en que suponemos en ello una concepción perfectamente banal del arte.

La oposición entre el arte y la realidad es, en efecto, completamente clásica. El arte es ficción. Cuando Goethe titula su biografía Verdad y Poesía, indica claramente que la poesía es otra cosas que la verdad -entendamos exactamente: otra cosa que las cosas tal como

* Traducción de Jorge Acevedo Guerra.

1 En L'art en liberté, Pocket, Paris, 2006; pp. 273-278.

2 François Fédier es filósofo. Nació en 1935. Ha sido discípulo de Jean Beaufret desde 1955. Se consagra, a partir de 1958, a la traducción de textos de Heidegger. Dirige la traducción, en curso, de la Edición Integral (Gesamtausgabe) de Heidegger en la editorial Gallimard. Él mismo ha traducido, entre otros mucho textos de ese filósofo, el volumen 65 de la Edición integral: "Apports à la philosophie. De l'avenance"; además, varios de sus Écrits politiques. También se ha dedicado a traducir a Hölderlin. Autor de numerosos libros, tales como Regarder Voir, "Entendre Heidegger et autres exercices d'écoute", Voz del amigo, Ediciones de la Universidad Diego Portales, Santiago, 2017.

$3 \quad$ "Proyecto de prefacio", Contre Sainte-Beuve, Gallimard, París, Pléiade, 1978, p. 216. [Versión en castellano: Contra Sainte-Beuve, Ed. Alianza, Madrid, 2016. Trad. de Silvia Acierno y Julio Baquero Cruz]. 
son realmente. Entre el arte y la realidad hay toda la diferencia que va de lo imaginario a lo real, de lo que se puede inventar libremente respecto a la "aridez de los hechos".

Si se ve el arte en esta oposición, lo que adviene como problema es el sentido en el que es preciso entender la recreación de que habla Proust. En efecto, no podría consistir en una reconstitución. ¿Podría haber algo más absurdo que el esfuerzo por rehacer (Proust, en una carta a Robert Dreyfus, escribe: para «contrahacer») aquello de lo cual se busca evadirse? ¿Es preciso, pues, entender recreación como volver a empezar, o, inclusive, como mejoramiento? En su primer libro, El nacimiento de la tragedia ${ }^{4}$, Nietzsche comprende así el arte apolíneo. Todo el arte apolíneo, explica Nietzsche, se propone transformar el devenir en forma. El devenir es la vida misma, con su fluidez aterradora, su dramática movilidad, donde lo que era felicidad deviene sufrimiento, donde la vida concluye necesariamente en la muerte. La forma eterniza. Ella inclusive fija, si se lo ve bien. Pero mírese una estatua de Apolo: lo que está fijado allí es la vida misma, de tal suerte que la forma no es la muerte del devenir, sino su elevación hasta el Ideal. En este sentido, el arte apolíneo es, justamente, recreación de la realidad, o inclusive idealización donde la realidad adquiere el aspecto de la belleza. Recrear la realidad, en la actualidad significa embellecer la realidad, como se lo puede verificar a propósito de todo aquello que se llama "arte académico". Él se define por la posesión de reglas o de cánones cuya función es precisamente servir en la recreación de la realidad. Un paisaje académico no consiste en tal o cual visión del campo, sino, con ocasión de un campo, componer un cuadro armonioso obedeciendo a las leyes de la simetría, del orden y de la medida. ¿Es Proust un artista académico? De ninguna manera. En consecuencia, "recrear la realidad" no puede querer decir idealizar o embellecer. La declaración, perdiendo su banalidad, se torna enigmática.

Hasta aquí, hemos comprendido banalmente la realidad como todo lo que nos rodea y nos está sucediendo, tanto lo cotidiano como lo extraordinario, tanto el medio donde vivimos como el conjunto del universo. Creemos obstinadamente que esta realidad -a la cual, como se dice, nada escapa- constituye la realidad del arte. Y parece que a propósito de eso podemos dar mil ejemplos: a la estación Saint-Lazare, que ha pintado Monet, vamos ocasionalmente a tomar el tren; en cuanto al león que pinta Rubens, su congénere ruge en el circo o caza en África; la familia real de Goya ha reinado, efectivamente, en España hacia fines del siglo XVIII.

Un solo hecho debe llevarnos a dudar que la relación de la realidad con el arte sea ésa: la existencia del arte "abstracto". La condición necesaria y suficiente para imponer la duda es que en él haya arte. Hoy día nadie tiene derecho a impugnarlo. Mondrian es un pintor en todo el sentido de la palabra, al igual que Kandinsky o, más cerca de nosotros, Jackson Pollock. Afirmarlo no significa nada. Es preciso probarlo. Ahora bien, la prueba

4 [El nacimiento de la tragedia, Ed. Alianza, Madrid, 1973. Trad. de Andrés Sánchez Pascual]. 
no puede ser sino una indicación para ir a verificarlo en la pintura ${ }^{5}$. Que un pintor sea un pintor significa que es capaz de "constituir un hecho pictórico" como dice Braque 6 Digamos: que él da lugar a un espacio pictórico. El espacio pictórico de Kandinsky es casi tan original como el de Cézanne. Pero ni el uno ni el otro son espacios reales, en el sentido de un espacio "natural"; el de la habitación donde descansamos, por ejemplo. El espacio cezanniano es aún más real, pero de una realidad que no se mide para nada con la realidad en su sentido habitual.

Ver un cuadro es ser capaz de percibir su espacio específico, su picturalidad, su sercuadro. Hay, así, un espacio propio de Mondrian. Pero, el muy sorprendente fenómeno de la picturalidad presenta esta característica esencial: el espacio tan particular de cada pintor es al mismo tiempo una de las facetas de un espacio aún más original -que es la unidad primera de todos los espacios pictóricos-, del que ninguno es su realización [del que ninguno es la realización; es decir, del que cada uno no es sino una realización] ${ }^{7}$. La realización -"realizar, todo está ahí", decía Cézanne-, es, pues, la constitución de un espacio verdaderamente pictórico que, a partir de este solo hecho, llega a corroborar las otras realizaciones, llega a confirmarlas, en el sentido en que, de época en época, las obras de los grandes artistas forman una constelación muy libre, en la que, según el decir de Braque, "el eco responde al eco, todo se repercute".

Realidad, pues, ya no significa la realidad "de todos los días", sino lo que el arte pone en obra [met en œuvre], en el sentido más estricto de la palabra -de tal modo que únicamente gracias al arte puede ser alcanzada esta realización. Proust, en El Tiempo recobrado, dice:

La verdadera vida, la vida por fin descubierta y aclarada, la única vida, por consiguiente, plenamente vivida, es la literatura ${ }^{9}$.

Henos aquí en las antípodas de la banalidad, en plena paradoja: en efecto, Proust acaba de decir que la realidad es el arte. Si retomamos nuestro punto de partida-el arte como

5 Cf. Émile Bernard, Conversations avec Cézanne, Macula, París, 1978; Cézanne a É. Bernard, 23 de octubre de 1905 [Versión en castellano: Conversaciones con Cézanne, Edición crítica presentada por P. M. Doran, Ed. Cactus, Buenos Aires, 2016, pp. 92 ss. Trad. de Pablo Ires].

6 Georges Braque, Le jour et la nuit. Cahiers 1917-1952, Gallimard, París, 1985, p. 13. [Versión en castellano: El día y la noche, Ed. Acantilado, Barcelona, 2001. Trad. de Ramón Andrés y Rosa Rius Gatell. Véase, François Vezin, "Braque, Georges (1882-1963)", en: Philippe Arjakosky, François Fédier, Hadrien France-Lanord (directores), Le Dictionnaire Martin Heidegger, Cerf, París, 2013, pp. 197 s.].

[Corchetes del autor].

$8 \quad$ Le jour et la nuit, ed. cit., p. 30.

$9 \quad$ À la recherche du temps perdu, Pléiade (éd. Clarac-Ferré), t. III, p. 895. [Versión en castellano: "El tiempo recobrado" de En busca del tiempo perdido (Tomo VII), Ed. Debolsillo, Buenos Aires, 2010, p. 220. Trad. de Carlos Manzano]. 
recreación de la realidad-constatamos ahora una confrontación. En efecto, si la realidad es la literatura, y la literatura, la recreación de la realidad, ¿no nos movemos en círculo?, y la fórmula de Proust ¿no es, en resumidas cuentas, sino una absurdidad?

El arte recrea la realidad, dice Proust: sabemos que la realidad designa lo real mismo; de alguna manera, lo admitido como real. Lo que importa comprender bien, en última instancia, es que sea preciso recrear la realidad. Aquí, recrear no puede tener más que un sentido: el de reconstituir lo que se deshace. Que el arte recree la realidad implica que la realidad, lejos de darse, no cesa de escaparse, de desvanecerse, de desaparecer. Hay, por decirlo así, dos formas de realidad: la realidad bruta e inmediata, tal como la cruzamos por momentos en la vida cotidiana, y la realidad creada por el arte. El arte es, de hecho, el paso de una a otra. En una nota sobre Rembrandt, Proust escribe:

Primero, las obras de un hombre pueden parecerse más a la naturaleza que a él mismo. Pero más tarde, esa esencia de él mismo que cada contacto con la naturaleza ha estimulado más, las impregna ya completamente. Y hacia el fin, es visible que ya no es sino eso lo que para él es la realidad, y que lucha cada vez más para darla por entero ${ }^{10}$.

La realidad -es preciso que, por fin, la captemos-, no es ni el mundo objetivo ni la pura subjetividad, sino la relación entre un hombre y el mundo, "el contacto genial con la naturaleza", dice Proust, cuidando de no ir en la dirección equivocada que propone el adjetivo genial. En efecto, todo contacto con la naturaleza percibido con toda lucidez como ese contacto - dicho de otra manera, todos los instantes de sensibilidad lúcida (Proust los llama "breves fogonazos" "11)-, es ipso facto genial, es decir, según el sentido latino de la palabra genialis, relativo al nacimiento; entendamos: naturalmente apto para la generación del arte. En la página 889 del Tiempo recobrado, Proust señala:
¿Acaso no me había puesto la propia naturaleza [...] en la vía del arte? ¿Acaso no era un comienzo de arte ella misma, que sólo me había permitido conocer, con frecuencia mucho tiempo después, la belleza de una cosa en otra: el mediodía en Combray sólo en el ruido de sus campanas, las reuniones vespertinas en Doncières sólo en los espasmos del calorífero de agua? ${ }^{12}$

La realidad es la relación de un ser humano con la naturaleza. En esta relación enraíza, como posibilidad del arte, la posibilidad de una relación explícita. Cuando esta estructura de relación ha llegado a ser el centro de la vida, cuando no se trata ya sino de recrear constantemente la realidad gracias a y en juego de relación...

10 Contre Sainte-Beuve, ed. cit., p. 660.

11 À la recherche du temps perdu, éd. Clarac-Ferré, t. III, p. 1032 (éd. Tadié, t. IV, p. 609). ["El tiempo recobrado", ed. cit., p. 364].

${ }_{12}$ Cf. éd. Tadié, p. 468. ["El tiempo recobrado", ed. cit., p. 214]. 
En la Matinée chez la princesse de Guermantes, p. 300, se puede leer:

Sólo, que las excusas no figuran en el arte, las intenciones no cuentan en él, en todo momento el artista debe escuchar a su instinto, razón por la cual el arte es la escuela más real, austera, de la vida y el verdadero Juicio Final ${ }^{13}$.

Recepción: 29/10/17

Aprobación: 31/11/17

13 Cf. À la recherche du temps perdu, éd. Tadié, t. IV, p. 458. [“El tiempo recobrado", ed. cit., pp. 203 s.]. 